\title{
A Systematic Review on International Health Policy and Services Research: A Bibliometric Analysis
}

\author{
Anqi He \\ Whuhan University \\ Yan Yu \\ Whuhan University \\ Si Zheng \\ Whuhan University \\ Mohammedhamid Osman kelifa \\ Whuhan University \\ Junfeng Jiang ( $\nabla_{\text {jiang0111@whu.edu.cn ) }}$ \\ Wuhan University https://orcid.org/0000-0001-6065-1591 \\ Peigang Wang \\ Whuhan University
}

\section{Research}

Keywords: bibliometrics, health policy and services, research hotspots, global health

Posted Date: November 6th, 2020

DOl: https://doi.org/10.21203/rs.3.rs-102665/v1

License: (c) (1) This work is licensed under a Creative Commons Attribution 4.0 International License.

Read Full License 


\section{Abstract}

Background: The number of research publications on health policy and services has been strikingly increasing. This study aimed to reveal the current status and trends of global research on health policy and services and provide insights for health policy and services research.

Methods: Based on the Social Science Citation Index (SSCI) database, research on health policy and services published between 1999 and 2018 were identified. The published journals, temporal trends, collaboration between countries/territories and research institutions, and hotspots in health policy and services' research were analyzed using bibliometric analysis.

Results: The number of health policy and services publications has been continuously increasing since 1999, especially after 2008. Health Affairs, Medical Care, and Health Services Research were the most active journals in this field. Scholars from the United States (US), the United Kingdom (UK) and Canada have published more related publications than other countries. Further, The US produced the largest number of independent and collaborative articles, and it took a central position in the collaboration network and had the greatest number of prolific institutions. Harvard University was the largest contributor of single-institution and collaborative publications and occupied a key position in collaborative networks. A keywords analysis demonstrated that medicare, quality of care, and primary care have always been researched hotspots in this field. The rankings of implementation, patient safety, and disparities have risen the most, suggesting a new research trend in the field since the 21 st century.

Conclusions: Our study identified the temporal and spatial characteristics, academic collaborations, and hotspots in scientific research output in the area of health policy and services. It can provide insights for health policy and services research and global health governance.

\section{Background}

With the deepening of medical and health system reform around the world, more and more attention has been paid to the role of health policy and services research in health decision-making. Health policy and services research belongs to a multi-disciplinary category, which integrates anthropology, political science, public health and other disciplines, and has significant characteristics of comprehensiveness and interdisciplinary. With the integration of relevant management sciences, sociology and economics, the research scope of health policy and services has been expanding [1], the number of publications has been increasing as well. As an effective medium for the dissemination of research results in this field, the publication outputs of health policy and services research becomes a platform for the full exchange and collision of relevant research ideas, and an important indicator to measure the development of this field [2]. Using scientific methods to analyze the publication outputs of health policy and services research is of great significance for understanding the current development status and future trends in this field.

Since the 21st century, bibliometrics has been widely used in statistics of papers in various disciplines, analysis of development trends, and evaluation of the influence of journals or research institutions, etc. It 
is a subject to explore the dynamic characteristics of science and technology using mathematical, statistical and other quantitative methods [3-4]. As a research tool and methodology, bibliometrics has formed a relatively scientific and objective international evaluation index system and has been applied to a variety of disciplines. At present, many scholars have carried out the bibliometric analysis in the field of medicine and health [5-7], but there are few systematic analyses on health policy and services research. Therefore, to better grasp the development status and future trends of health policy and services research, this paper selected the top ten journals of health policy and services research, based on the SSCl database. A systematic analysis of all the articles published in these ten journals from 1999 to 2018 was performed using a bibliometric method, hoping to provide some insights for health policy researchers and policymakers worldwide.

\section{Methods}

Data used in this study were retrieved from the SSCl database in the Web of Science. Top ten journals were selected according to the average ranking score of the impact factor in the past five years. A total of 68,717 published papers in these ten journals during 1999-2018 were retrieved. Only articles were included in our analysis, and other document types such as abstract, correction, editorial material, letters and notes were excluded. Finally, a total of 16,965 articles were included in the bibliometric analysis.

All articles published in the top ten journals from 1999 to 2018 were downloaded to Excel 2016 for descriptive statistical analysis. Gephi9.1 was used to perform a visual network analysis of collaboration between countries/territories and institutions. Python3.8.2 was used to perform geocoding, and ArcGIS10.3 was used to draw the author's geographic distribution map. The statistical deadline for publication retrieval and citations was May 2nd, 2019. Besides, articles from England, Scotland, Northern Ireland, and Wales were unified as articles from the UK. China's articles only included those from the mainland, while those from Taiwan and Hong Kong-China were analyzed separately due to their large number (no article from Macao China was included).

\section{Results}

\section{Journal analysis}

When it comes to journal publications, it is might not give a clear picture to evaluate only the impact factor of journals or the number of citations of papers. Therefore, we simultaneously used the total publications, total citation count, and impact factor to make the results more comprehensive [8]. The total publications, total citation count, average citations, 5-year impact factor of the top 10 journals in health policy and services research are summarized in Table 1. Health Affairs published the largest number of health policy and services related publications (4319, or $25.46 \%$ of the total number of publications), followed by Medical Care (3305, or 19.48\% of the total number of publications) and Health Services Research $(2198$, or $12.96 \%$ of the total number of publications). Health Affairs was the most cited journal, 
and Milbank Quarterly had the most average citations in a single publication and had the highest 5-year impact factor in the top 10 journals.

Table 1

The top 10 journals in health policy and services research

\begin{tabular}{|c|c|c|c|c|}
\hline Journal Title & $\mathrm{TP}(\%)$ & $\mathrm{TC}$ & $\mathrm{TC} / \mathrm{TP}$ & IF(5 year) \\
\hline Health Affairs & $\begin{array}{l}4319 \\
(25.46)\end{array}$ & 136214 & 31.54 & 5.53 \\
\hline Medical Care & $\begin{array}{l}3305 \\
(19.48)\end{array}$ & 135036 & 40.86 & 3.67 \\
\hline Health Services Research & $\begin{array}{l}2198 \\
(12.96)\end{array}$ & 62326 & 28.36 & 3.25 \\
\hline Value in Health & $\begin{array}{l}1811 \\
(10.67)\end{array}$ & 42432 & 23.43 & 5.64 \\
\hline Health Policy and Planning & $\begin{array}{l}1414 \\
(8.33)\end{array}$ & 28901 & 20.44 & 3.28 \\
\hline Implementation Science & $\begin{array}{l}1335 \\
(7.87)\end{array}$ & 31846 & 23.85 & 5.36 \\
\hline BMJ Quality \& Safety & $\begin{array}{l}796 \\
(4.69)\end{array}$ & 14060 & 17.66 & 6.46 \\
\hline $\begin{array}{l}\text { Administration and Policy in Mental Health and Mental } \\
\text { Health Services Research }\end{array}$ & $\begin{array}{l}771 \\
(4.54)\end{array}$ & 13655 & 17.71 & 2.98 \\
\hline Pharmacoeconomics & $\begin{array}{l}678 \\
(4.00)\end{array}$ & 12776 & 18.84 & 3.50 \\
\hline Milbank Quarterly & $\begin{array}{l}338 \\
(1.99)\end{array}$ & 16241 & 48.05 & 7.19 \\
\hline
\end{tabular}

\section{Characteristics of publication outputs}

Table 2 summarizes the temporal evolution of major scientific productivity descriptors between 1999 and 2018. The annual total publications, number of authors, cited references, page count, total citation count in the area of health policy and services research slightly fluctuated but considerably increased. The average number of authors, references, pages, and citations per article slightly fluctuated during this period with an overall average of $4.69,34.31$ and 11.70 , respectively. Only $5820(34.31 \%)$ health policy and services related articles were published between 1999 and 2008, and the number of these publications nearly doubled to 11,145 (65.69\%) between 2009 and 2018 . The average number of references per article varied over the years, from 26.65 in 1999 to 38.43 in 2018 . The significant increase in the number of publications and references per article between 1999 and 2018 indicated a stable 
growth and communication in the health policy and services research field during the past two decades. To some extent, the number of citations can mostly reflect the influence of an article on its research field. The number of citations per article decreased from 50.18 in 1999 to 1.45 in 2018. Despite this, the influence of these research outputs remained unknown considering the time of publications.

Table 2

Characteristics of publication outputs by year

\begin{tabular}{|llllllllll|}
\hline Years & TP & Au & Au/P & NR & NR/P & PG & PG/P & TC & TC/P \\
\hline 1999 & 450 & 1595 & 3.54 & 11993 & 26.65 & 5559 & 12.35 & 22581 & 50.18 \\
\hline 2000 & 433 & 1501 & 3.47 & 11401 & 26.33 & 5294 & 12.23 & 20674 & 47.75 \\
\hline 2001 & 430 & 1607 & 3.74 & 12669 & 29.46 & 5458 & 12.69 & 25807 & 60.02 \\
\hline 2002 & 514 & 1812 & 3.53 & 15311 & 29.79 & 6451 & 12.55 & 29037 & 56.49 \\
\hline 2003 & 546 & 1953 & 3.58 & 16087 & 29.46 & 6705 & 12.28 & 26655 & 48.82 \\
\hline 2004 & 596 & 2169 & 3.64 & 18131 & 30.42 & 7023 & 11.78 & 27299 & 45.80 \\
\hline 2005 & 627 & 2465 & 3.93 & 18476 & 29.47 & 7001 & 11.17 & 35624 & 56.82 \\
\hline 2006 & 677 & 2621 & 3.87 & 20558 & 30.37 & 7536 & 11.13 & 25947 & 38.33 \\
\hline 2007 & 751 & 3253 & 4.33 & 22090 & 29.41 & 8295 & 11.05 & 33677 & 44.84 \\
\hline 2008 & 796 & 3454 & 4.34 & 25439 & 31.96 & 8638 & 10.85 & 31614 & 39.72 \\
\hline 2009 & 937 & 4026 & 4.30 & 29338 & 31.31 & 9780 & 10.44 & 37013 & 39.50 \\
\hline 2010 & 981 & 4350 & 4.43 & 31564 & 32.18 & 9554 & 9.74 & 33162 & 33.80 \\
\hline 2011 & 1126 & 5492 & 4.88 & 38141 & 33.87 & 11122 & 9.88 & 33929 & 30.13 \\
\hline 2012 & 1130 & 5689 & 5.03 & 39862 & 35.28 & 11955 & 10.58 & 30349 & 26.86 \\
\hline 2013 & 1061 & 5374 & 5.07 & 39715 & 37.43 & 11186 & 10.54 & 26512 & 24.99 \\
\hline 2014 & 1190 & 6184 & 5.20 & 42769 & 35.94 & 12085 & 10.16 & 20202 & 16.98 \\
\hline 2015 & 1085 & 5764 & 5.31 & 41774 & 38.50 & 11561 & 10.66 & 14354 & 13.23 \\
\hline 2016 & 1168 & 6444 & 5.52 & 44729 & 38.30 & 12478 & 10.68 & 11292 & 9.67 \\
\hline 2017 & 1201 & 6770 & 5.64 & 45418 & 37.82 & 12561 & 10.46 & 5921 & 4.93 \\
\hline 2018 & 1266 & 7294 & 5.76 & 48656 & 38.43 & 14922 & 11.79 & 1838 & 1.45 \\
\hline $\begin{array}{l}\text { TP, total publications; AU, number of authors; NR, cited references; PG, page count; TC, total citation } \\
\text { count; AU/TP,NR/TP,PG/TP, and TC/TP, average number of authors, references, pages, and citations }\end{array}$ \\
\hline per article. & & & & & & & & \\
\hline & & & & & & & & & \\
\hline
\end{tabular}




\section{Geography analysis}

A total of 16,485 articles were used for the geography analysis, as 480 articles lacked the information of authors' address. We extracted the geographic coordinates of 52,452 authors using python geocoding, then we used ArcGIS to present the latitude and longitude coordinates in the form of geocoded dots to reflect the spatial distribution of the number of articles published. The higher the density of dots in an area, the more articles published in that area. As can be seen from Fig. 1, the authors who studied health policy and services were distributed worldwide. The major spatial clusters of these authors were mainly located in North America and Europe, the other minor clusters were distributed in Eastern Asia, Southeastern Australia, Southern South America, Eastern and Western Africa, and only a few cluster dots were distributed in North Africa, Central Asia, and North Asia. These phenomena illustrated that the research interest of health policy and services varies among regions around the world, but authors in Europe and North America do better.

\section{Countries/territories analysis}

The contribution of different countries/territories was estimated based on the location of the authors' affiliated countries/territories. Articles signed by authors from the same countries/territories were defined as single-country publications (SP); articles signed by authors from different countries/territories were defined as internationally collaborative publications (CP). The top 20 most productive countries/territories between 1999 and 2018 were summarized in Table 3, and they were ranked in terms of their total number of publications. The US outranked 149 other countries/territories with 12,421 publications, where 10,490 were solely produced by authors from the US and 1931 were international collaborations. The UK published the second largest number of total publications, followed by Canada, Netherlands and Australia. Among the top 20 most productive countries/territories, the number of internationally collaborative publications in 19 countries/territories outnumbered their single-country publications except for the US. Uganda had the highest proportion of internationally collaborative publications in its total publications (92.93\%), whereas the US had the highest proportion of singlecountry publications in its total publications (84.45\%). Out of these 20 countries/territories, 12 were from Europe, three were from Asia, two were from North America, two were from Africa and only one was from Oceania. We also found that the number of academic outputs was affected by the economic development of a country. Most of these top 20 countries/territories were developed countries/territories. 
Table 3

The top 20 most productive countries/territories between 1999 and 2018

\begin{tabular}{|c|c|c|c|c|c|c|}
\hline Country/territory & TP & $\%$ & SP & SP/TP & $\mathrm{CP}$ & $\mathrm{CP} / \mathrm{TP}$ \\
\hline USA & 12421 & 73.22 & 10490 & 84.45 & 1931 & 15.55 \\
\hline UK & 2190 & 12.91 & 766 & 34.98 & 1424 & 65.02 \\
\hline Canada & 1360 & 8.02 & 597 & 43.90 & 763 & 56.10 \\
\hline Netherlands & 719 & 4.24 & 305 & 42.42 & 414 & 57.58 \\
\hline Australia & 618 & 3.64 & 224 & 36.25 & 394 & 63.75 \\
\hline Switzerland & 329 & 1.94 & 34 & 10.33 & 295 & 89.67 \\
\hline Germany & 313 & 1.84 & 90 & 28.75 & 223 & 71.25 \\
\hline Sweden & 233 & 1.37 & 63 & 27.04 & 170 & 72.96 \\
\hline France & 211 & 1.24 & 45 & 21.33 & 166 & 78.67 \\
\hline South Africa & 196 & 1.16 & 25 & 12.76 & 171 & 87.24 \\
\hline Belgium & 186 & 1.10 & 37 & 19.89 & 149 & 80.11 \\
\hline Norway & 157 & 0.93 & 39 & 24.84 & 118 & 75.16 \\
\hline Spain & 155 & 0.91 & 50 & 32.26 & 105 & 67.74 \\
\hline China & 144 & 0.85 & 28 & 19.44 & 116 & 80.56 \\
\hline Italy & 140 & 0.83 & 41 & 29.29 & 99 & 70.71 \\
\hline India & 138 & 0.81 & 32 & 23.19 & 106 & 76.81 \\
\hline Denmark & 110 & 0.65 & 38 & 34.55 & 72 & 65.45 \\
\hline Taiwan & 106 & 0.62 & 50 & 47.17 & 56 & 52.83 \\
\hline Uganda & 99 & 0.58 & 7 & 7.07 & 92 & 92.93 \\
\hline Ireland & 96 & 0.57 & 23 & 23.96 & 73 & 76.04 \\
\hline \multicolumn{7}{|c|}{$\begin{array}{l}\text { TP total publications, SP single-country publications, CP internationally collaborative publications, } \\
\text { SP/TP percentage of single-country publications in the total number of publications, CP/TP } \\
\text { percentage of collaborative publications in the total number of publications, \% percentage of total } \\
\text { articles. }\end{array}$} \\
\hline
\end{tabular}

The collaborative network of the top 20 most productive countries/territories was further visualized using Gephi (Fig. 2). Each node symbolizes a country/territory. The larger the nodes in the figure, the larger number of collaborative publications published in that country/territory. The thickness of the connecting line represents the strength of collaboration between any two countries/territories [9]. As can be seen 
from Fig. 2, the top 20 most productive countries/territories frequently collaborated. The US was identified as the major collaborator of some productive countries, including the UK, Canada, Switzerland, and the Netherlands. In addition, the UK had also a lot of collaboration with Canada and the Netherlands.

\section{Institutions analysis}

The contribution of different institutions was estimated according to the affiliated institution of authors. Similar to countries/territories analysis, articles signed by authors from the same institution were defined as single-institution publications (SP); articles signed by authors from different institutions were defined as cross-institution collaborative publications (CP). The most productive institution was Harvard University with 1292 articles, followed by the University of California Los Angeles with 624 articles, the University of Michigan with 580 articles, the University of Washington with 578 articles and RAND Corporation with 577 articles (see Table 4). Harvard University published the largest number of singleinstitution publications with 140 articles, followed by the University of Pennsylvania, almost half of the former with 75 articles. Harvard University also published the largest number of cross-institution collaborative publications, followed by the University of California Los Angeles, and the University of Washington. Most of these institutions were universities, only four of them were companies or hospitals; a total of 18 institutions were from the US, one was from Canada, and one from the UK. 
Table 4

The top 20 most productive institutions between 1999 and 2018

\begin{tabular}{|lllllll|}
\hline Institution & TP & $\%$ & SP & SP/TP & CP & CP/TP \\
\hline Harvard Univ,USA & 1292 & 7.62 & 140 & 10.84 & 1152 & 89.16 \\
\hline Univ Calif Los Angeles,USA & 624 & 3.68 & 34 & 5.45 & 590 & 94.55 \\
\hline Univ Michigan,USA & 580 & 3.42 & 71 & 12.24 & 509 & 87.76 \\
\hline Univ Washington,USA & 578 & 3.41 & 52 & 9.00 & 526 & 91.00 \\
\hline RAND Corp,USA & 577 & 3.40 & 74 & 12.82 & 503 & 87.18 \\
\hline Univ Penn,USA & 537 & 3.17 & 75 & 13.97 & 462 & 86.03 \\
\hline Univ Calif San Francisco,USA & 500 & 2.95 & 72 & 14.40 & 428 & 85.60 \\
\hline Brigham \& Womens Hosp,USA & 395 & 2.33 & 6 & 1.52 & 389 & 98.48 \\
\hline Univ Toronto,Canada & 372 & 2.19 & 9 & 2.42 & 363 & 97.58 \\
\hline Univ N Carolina,USA & 368 & 2.17 & 49 & 13.32 & 319 & 86.68 \\
\hline Stanford Univ,USA & 360 & 2.12 & 34 & 9.44 & 326 & 90.56 \\
\hline Boston Univ,USA & 349 & 2.06 & 15 & 4.30 & 334 & 95.70 \\
\hline Yale Univ,USA & 347 & 2.05 & 33 & 9.51 & 314 & 90.49 \\
\hline Johns Hopkins Bloomberg Sch Publ Hlth,USA & 340 & 2.00 & 18 & 5.29 & 322 & 94.71 \\
\hline Univ Minnesota,USA & 331 & 1.95 & 48 & 14.50 & 283 & 85.50 \\
\hline Johns Hopkins Univ,USA & 324 & 1.91 & 32 & 9.88 & 292 & 90.12 \\
\hline Duke Univ,USA & 324 & 1.91 & 43 & 13.27 & 281 & 86.73 \\
\hline Columbia Univ,USA & 308 & 1.82 & 40 & 12.99 & 268 & 87.01 \\
\hline London Sch Hyg \& Trop Med,UK & 296 & 1.74 & 19 & 6.42 & 277 & 93.58 \\
\hline Univ Chicago,USA & 278 & 1.64 & 36 & 12.95 & 242 & 87.05 \\
\hline TP total publications, SP single-institution publications, CP cross-institution collaborated publications, \\
\hline $\begin{array}{l}\text { SP/TP percentage of single-institution publications in the total number of publications, CP/TP } \\
\text { articles. }\end{array}$ & & & & & & \\
\hline
\end{tabular}

The collaboration network of the top 20 most productive institutions is shown in Fig. 3. As a central point, Harvard University had strong collaborative relationships with Brigham Women's Hospital, RAND Corporation, the University of California Los Angeles, the University of Michigan and Yale University. In addition, the University of California Los Angeles had strong collaborative relationships with RAND 
Corporation, the Universities of Washington and California San Francisco. The Universities of Washington, Pennsylvania and Duke also had close collaborations, while the collaboration among other institutions was relatively fewer.

\section{Keywords analysis}

Keywords usually reflect the topic of an article. Keyword analysis can help us to identify research hotspots and trends. The keywords in the collected articles were divided and ranked in five time periods (1999-2003, 2004-2008, 2009-2013, and 2014-2018) (see Table 5). The arrows in Table 5 indicate changes in the rankings of these keywords. The five most frequently used keywords for all periods were "Medicare", "Quality of care", "Implementation," "Cost-effectiveness", and "Primary care". In the last two decades, the rankings of keywords in this area have been constantly changing, but the rankings of "Medical", "Quality of care", and "Primary care" have been consistently ranked in the top ten, indicating that these topics were invariable hotspots in this field. The three keywords with the biggest changes in the ranking were "Implementation", "Patient safety", and "Disparities", rising from the 130th, 740th, and 266th in 1999-2003 to the 1st, 14th and 16th in 2014-2018, respectively. These words attracted growing attention during the past 20 years and might become a new focus in the future. 
Table 5

Temporal evolution of the 20 most frequently used keywords

\begin{tabular}{|c|c|c|c|c|c|c|c|c|c|c|}
\hline \multirow[t]{2}{*}{ Key words } & \multicolumn{2}{|c|}{ Total } & \multicolumn{2}{|c|}{ 1999-2003 } & \multicolumn{2}{|c|}{ 2004-2008 } & \multicolumn{2}{|c|}{ 2009-2013 } & \multicolumn{2}{|c|}{ 2014-2018 } \\
\hline & $\mathbf{P}$ & $\mathbf{R}$ & $\mathbf{P}$ & $\mathbf{R}$ & $\mathbf{P}$ & $\mathbf{R}$ & $\mathbf{P}$ & $\mathbf{R}$ & $\mathbf{P}$ & $\mathbf{R}$ \\
\hline Medicare & 416 & 1 & 72 & 3 & 81 & 3 & 110 & 3 & 153 & 3 \\
\hline quality of care $\downarrow$ & 398 & 2 & 76 & 2 & 96 & 2 & 113 & 2 & 113 & 6 \\
\hline Implementation $\uparrow$ & 349 & 3 & 6 & 130 & 13 & 82 & 92 & 4 & 238 & 1 \\
\hline Cost-effectiveness $\uparrow$ & 326 & 4 & 31 & 12 & 71 & 6 & 127 & 1 & 97 & 9 \\
\hline Primary care $\uparrow$ & 324 & 5 & 37 & 6 & 59 & 7 & 71 & 7 & 157 & 2 \\
\hline Medicaid $\uparrow$ & 324 & 5 & 41 & 5 & 100 & 1 & 57 & 11 & 126 & 4 \\
\hline Quality improvement $\uparrow$ & 277 & 7 & 19 & 24 & 50 & 8 & 84 & 5 & 124 & 5 \\
\hline quality of life $\downarrow$ & 239 & 8 & 55 & 4 & 77 & 5 & 73 & 6 & 34 & 42 \\
\hline Mental health $\uparrow$ & 229 & 9 & 24 & 19 & 49 & 9 & 50 & 14 & 106 & 7 \\
\hline managed care $\downarrow$ & 217 & 10 & 97 & 1 & 79 & 4 & 28 & 44 & 13 & 202 \\
\hline health policy $\uparrow$ & 207 & 11 & 14 & 40 & 25 & 39 & 63 & 9 & 105 & 8 \\
\hline health insurance $\downarrow$ & 178 & 12 & 31 & 12 & 48 & 10 & 38 & 26 & 61 & 17 \\
\hline Veterans $\downarrow$ & 174 & 13 & 34 & 9 & 30 & 28 & 31 & 38 & 79 & 11 \\
\hline Depression $\downarrow$ & 170 & 14 & 34 & 9 & 47 & 11 & 42 & 20 & 47 & 24 \\
\hline patient safety $\uparrow$ & 166 & 15 & 1 & 740 & 39 & 17 & 57 & 11 & 69 & 14 \\
\hline health services research $\uparrow$ & 161 & 16 & 17 & 31 & 31 & 26 & 43 & 19 & 70 & 13 \\
\hline quality $\uparrow$ & 160 & 17 & 19 & 24 & 42 & 13 & 49 & 16 & 50 & 22 \\
\hline mortality $\downarrow$ & 160 & 17 & 37 & 6 & 39 & 17 & 46 & 18 & 38 & 35 \\
\hline Diabetes $\uparrow$ & 160 & 17 & 7 & 104 & 34 & 24 & 62 & 10 & 57 & 19 \\
\hline Disparities $\uparrow$ & 158 & 20 & 3 & 266 & 45 & 12 & 47 & 17 & 63 & 16 \\
\hline
\end{tabular}

\section{Discussion}

Based on the bibliometric method, this study conducted a systematic review of international health policy and services research between 1999 and 2018. The present study collected and analyzed information from the top 10 academic journals in health policy and services research. This study has obtained a series of substantive results in the international distribution of related research, collaboration relations, 
hotspots development trends, etc., which could help to discover existing caveats in the current health policy and services research and provide some insights for the development of related research and global health action in the future.

This study found that authors in the field of health policy and services are mainly from North America and Europe, which was closely and positively related to the country's economic and social development [10]. Developed countries headed by the US are still the main forces in current health policy and services research. Top universities in the US such as Harvard University and the University of California were in a leading position in this research field, and the US is far more independent in high-level research than other countries. The independence of the US in this field was attributed to its strong economic foundation and the long-term leadership in technological development, with a large number of top academic research institutions (see Table 4) and good academic collaboration between them (see Fig. 3). However, these top academic research institutions had a lot of collaboration in this field within the US, but they had an insufficient collaboration with institutions in other countries, especially research institutions in developing countries. Since health policy and services need to be closely integrated with the actual development of the local society, this low academic openness (internal collaboration in developed countries rather than collaboration between developed and developing countries) may not be conducive to the healthcare development of developing countries. Another noteworthy phenomenon was that with the rapid development of social economy and scientific research investment, China, India, and Uganda have entered the top 20 in the total number of articles published in the field of health policy and services, but their overall rankings were still relatively low. These countries have a relatively low proportion of singlecountry publications(see Table 3), which indicates that their independent publication ability is relatively weak currently, and they rely more on collaborated publications to output high-level scientific research in this field.

It was worth paying attention to the characteristics of the publication outputs. With the passage of time and the development of health policy and services research, more and more articles had been published in high-level research journals, so articles available for reference were becoming more abundant, and scholars also paid more attention to collaborative research. This reflects a good and sustainable developmental trend of health policy and services research. It should be noted that the average number of pages has been decreasing within the last 20 years, which can be attributed to two main reasons. Firstly, the empirical research paradigm has become more and more powerful since the 21 st century, and it is now the mainstream research method [11]. The Alliance for Health Policy and Systems Research (AHPSR) of the World Health Organization (WHO) has also emphasized that health policy research requires evidence-based methods [12], which makes the number of empirical research on health policy and services to increase and the relative number of theoretical research to decline. As the length of empirical research was shorter than that of theoretical research in the initial stage of its development, the average number of pages per article decreased. With the integration and development of the two research paradigms, empirical research has begun to emphasize in-depth discussions and review of theory and literature, hence the length of the paper has gradually increased. Secondly, in the early years of the $21 \mathrm{st}$ century, several journals underwent form revisions, which resulted in a decrease in the number of pages 
with the same number of words. For example, Health Affairs, which had the largest number of articles published, underwent a form revision in early 2010, and it reduced the space occupied by papers in the journal while keeping the number of words unchanged. In recent years after the stabilization of the form revision, the number of pages per article has shown a steady increase.

There were several characteristics worthy of attention in terms of research hotspots. First of all, many research hotspots were imprinted by the characteristics of the US. For example, Medicare and Medicaid are two famous social medical insurance systems in the US, and their evaluation and reform have always been the focus of many scholars [13-14]. In our analysis, this may be due to the fact that most articles in the SSCI database are from the US, and most influential research institutions are also in the US. Health policy research in other countries should take the characteristics of their health system into account when drawing lessons from the US. Secondly, the word "quality" always appeared in several keywords (e.g., quality of care, quality improvement, quality of life), which indicates that the research has long-term concern for the quality of health policy and services, which is consistent with previous research results [15]. Thirdly, researchers pay more attention to health policy, cost-effectiveness analysis and health policy implications, which reflects the increasing popularity of the pragmatic trend that scientific research serves social and economic development. Fourth, the disparity in the utilization of health services has gradually attracted attention, which is one of the most important characteristics of health policy and services research in the current research stage. In the early stage of health policy research, the level of healthcare development was relatively low, and researchers paid more attention to examining health policy and services from a holistic perspective. With the improvement of the health service level of advantaged groups, the vulnerable status of disadvantaged groups in health services has attracted more attention from researchers and policymakers, so they began to keep a watchful eye on healthcare disparities. Finally, the research focus has shifted from general to specific points, which is manifested in the decreasing frequency of general health outcomes such as depression, mortality, and quality of life, and the increasing frequency of specific health outcomes such as diabetes. This shift reflects the gradual refinement of health policy and services research. Combined with the feature of increasing attention to primary health care, this shift also reflects the phenomenon that the global disease spectrum is shifting from infectious diseases to chronic non-communicable diseases [16].

Although this research attempted to comprehensively display the research characteristics and changes in the field of health policy and services and to provide insights for the future development of related research, there were still some limitations. First of all, although 10 journals with higher influence were selected for analysis based on the ranking of impact factors, this may not be enough to cover all the highquality researches in this field, because some researches have not been published in these 10 journals. Thus, there may be some biases in our results. Secondly, this study did not provide a detailed presentation of the collaboration network between scholars at the micro-level, because the software used cannot properly capture the information of authors' cooperation; thus, only international differences and transnational collaboration characteristics of academic collaboration relationship at the national level were analyzed, which made it difficult to show the development of the school and academic community of health policy and services research. Finally, the data used in this study only came from the SSCI 
database. The articles included were mainly from the social sciences but few articles in the natural sciences, which couldn't fully reflect the research on health policy and services in a broader sense. Both $\mathrm{SSCl}$ and $\mathrm{SCl}$ databases should be discussed in further work, and more accurate and efficient identification methods should be used to capture more information from other related research areas.

\section{Declarations}

\section{Ethics approval and consent to participate}

Not applicable.

\section{Consent for publication}

Not applicable.

\section{Availability of data and material}

No additional data are available.

\section{Competing interests}

The authors declare that they have no competing interests.

\section{Funding}

This work was supported by the China Medical Board Open Competition (CMB-OC) Research Program "Research on Equalization of Basic Public Health Services for Rural-to-urban Migrants in China" [grant number 17-273].

\section{Authors' contributions}

Wang designed the study; He, Yu and Zheng collected and analyzed the data; He, Yu, Zheng and Jiang wrote the manuscript; all authors revised and reviewed the manuscript.

\section{Acknowledgements}

Not applicable.

\section{References}

1. Gilson L: Introduction to health policy and systems research. China Health Policy Research, 2013, 6(01): 62-70.

2. Hsu YHE, Ho YS: Highly cited articles in health care sciences and services field in science citation index expanded a bibliometric analysis for 1958-2012. Methods of Information in Medicine, 2014, 53(6): 446-58. 
3. Gaviria-Marin M, Merigo JM, Baier-Fuentes H: Knowledge management: A global examination based on bibliometric analysis. Technological Forecasting and Social Change, 2019, 140, 194-220.

4. Qiu JP: Bibliometrics. Beijing: Science and Technology Literature Press; 1998

5. Gao C, Yao M, Hu L, Ren GH, Chi CH: Metrological Study of the Hospice Care Delivered by Community Health Service Centers in China. Chinese General Practice, 2017, 20(34): 4237-4241.

6. Li X, Hao JY: Bibliometric analysis of core periodicals of military medicine based on SCl. Military medicine, 2016, 40(12): 994-8.

7. Lin P, Sun CP, Li Y, Chen WZ: The Bibliometric Indicators Analysis of Medical Core Journals Hosted by Beijing,Shanghai and Guangzhou. Medicine and Society, 2015, 28(06): 27-30.

8. Sun QL: The Researches on the Relationship of Impact Factors, Cited Times and Download Times. Guangxi Normal University, 2015.

9. Wang HJ, He QQ, Liu XJ, Zhuang YH, Hong S: Global urbanization research from 1991 to 2009: A systematic research review. Landscape and Urban Planning, 2012, 104(3-4): 299-309.

10. Dai T: The characteristic of health policy research and the use of health policy information resource. China Health Policy Research, 2008, 1(01): 58-62.

11. Meng Y: Empirical research is still the mainstream research paradigm. University Education Science, 2011, 05: 89-91.

12. Hu SL: Progress in research methods of evidence-based decision making. Health Economics Research, 2006(08): 39-40.

13. Zhu ZR, Zhang LL, Yan JG, Shao R: Reform Course and Driving Factors of American Medicare Payment Mode and Implication for China. Chinese Pharmacy, 2020, 31(05): 545-549.

14. Zhao WW: A Comparative Study of China-US Medical Reform--Taking the US Medicaid Program and China's New Rural Cooperative System as an example. People's Forum, 2016(31): 184-185.

15. Qi MJ, Bao YQ, Han YL: Progress of international health policy:Bibliometric analysis based on CiteSpace. China Health Policy Research, 2017, 10(07): 6-12.

16. Zhou T, Guan HJ, Yao JQ, Xiong XM,Ma AX: The quality of life in Chinese population with chronic non-communicable diseases according to EQ-5D-3L: a systematic review. Quality of Life Research, 2018, 27(11): 2799-814.

\section{Figures}




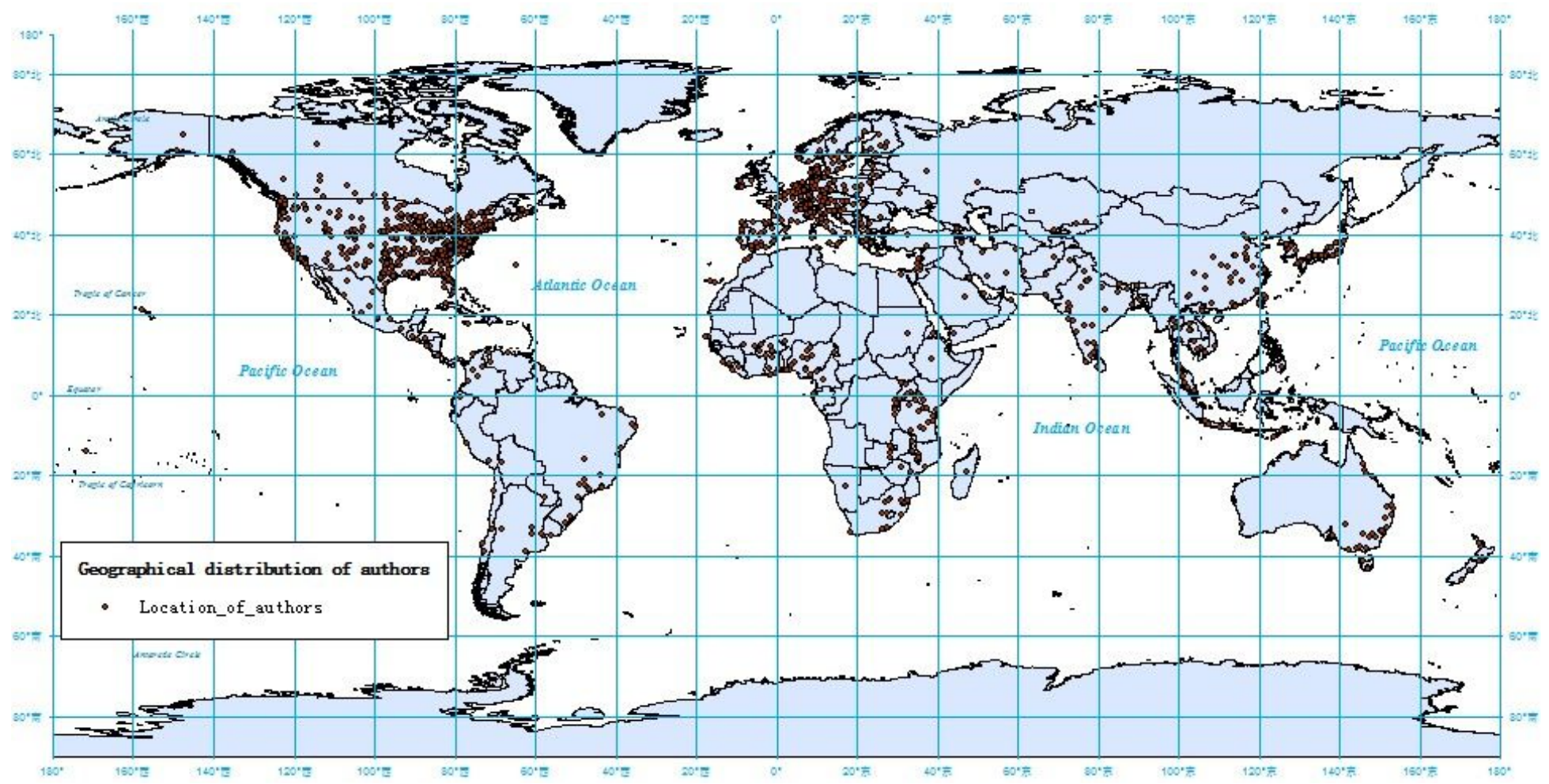

Figure 1

Global geographic distribution of authors (1999-2018) Note: The designations employed and the presentation of the material on this map do not imply the expression of any opinion whatsoever on the part of Research Square concerning the legal status of any country, territory, city or area or of its authorities, or concerning the delimitation of its frontiers or boundaries. This map has been provided by the authors. 


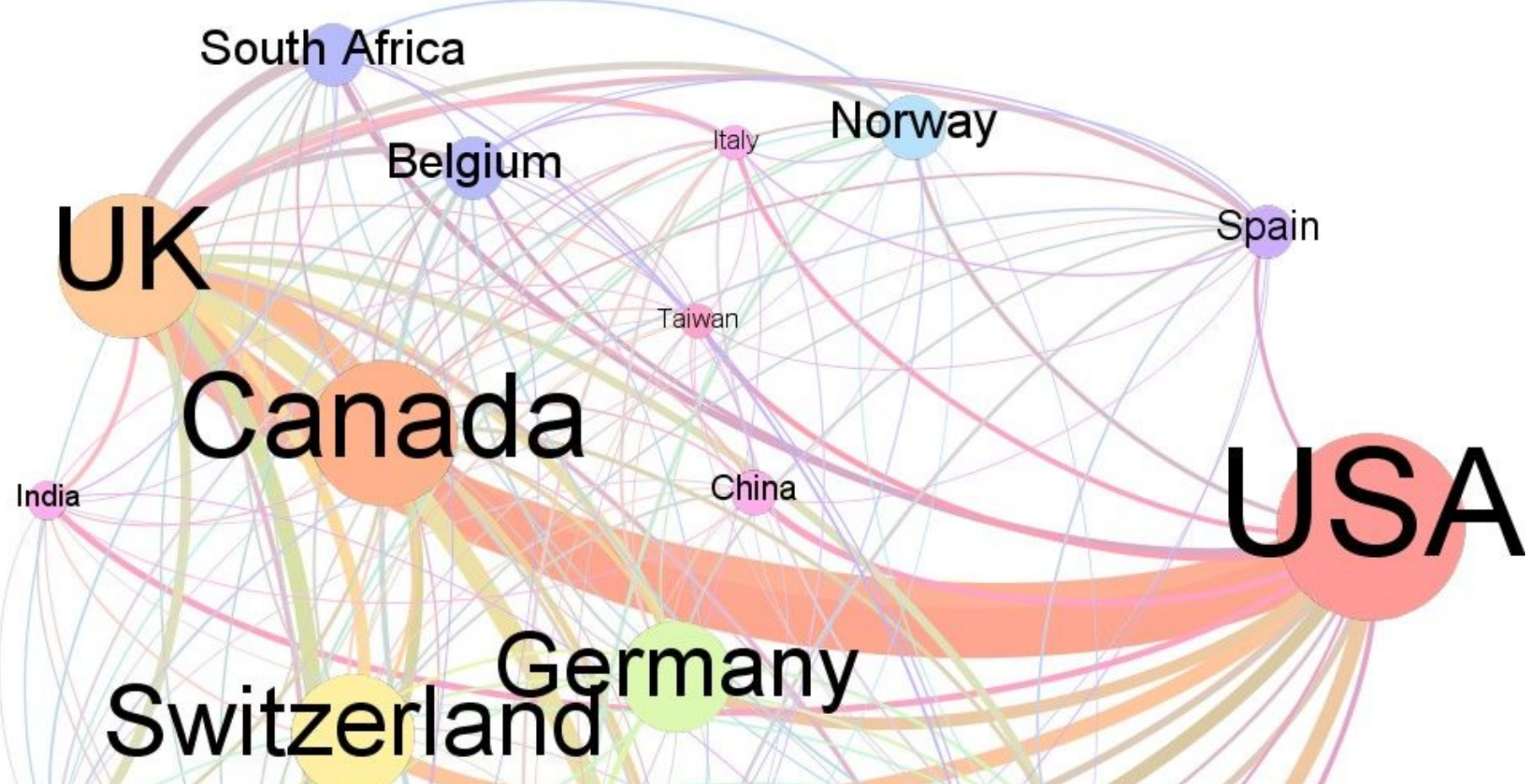

Sweden

France

Australia Denmark

Ireland

\section{Uganda}

Netherlands

Figure 2

Collaboration network of the top 20 most productive countries/territories 
Yale Univ,USA

\section{Univ Calif San Francisco, USA}

Johns Hopkins Bloomberg Sch Publ HIth, USA

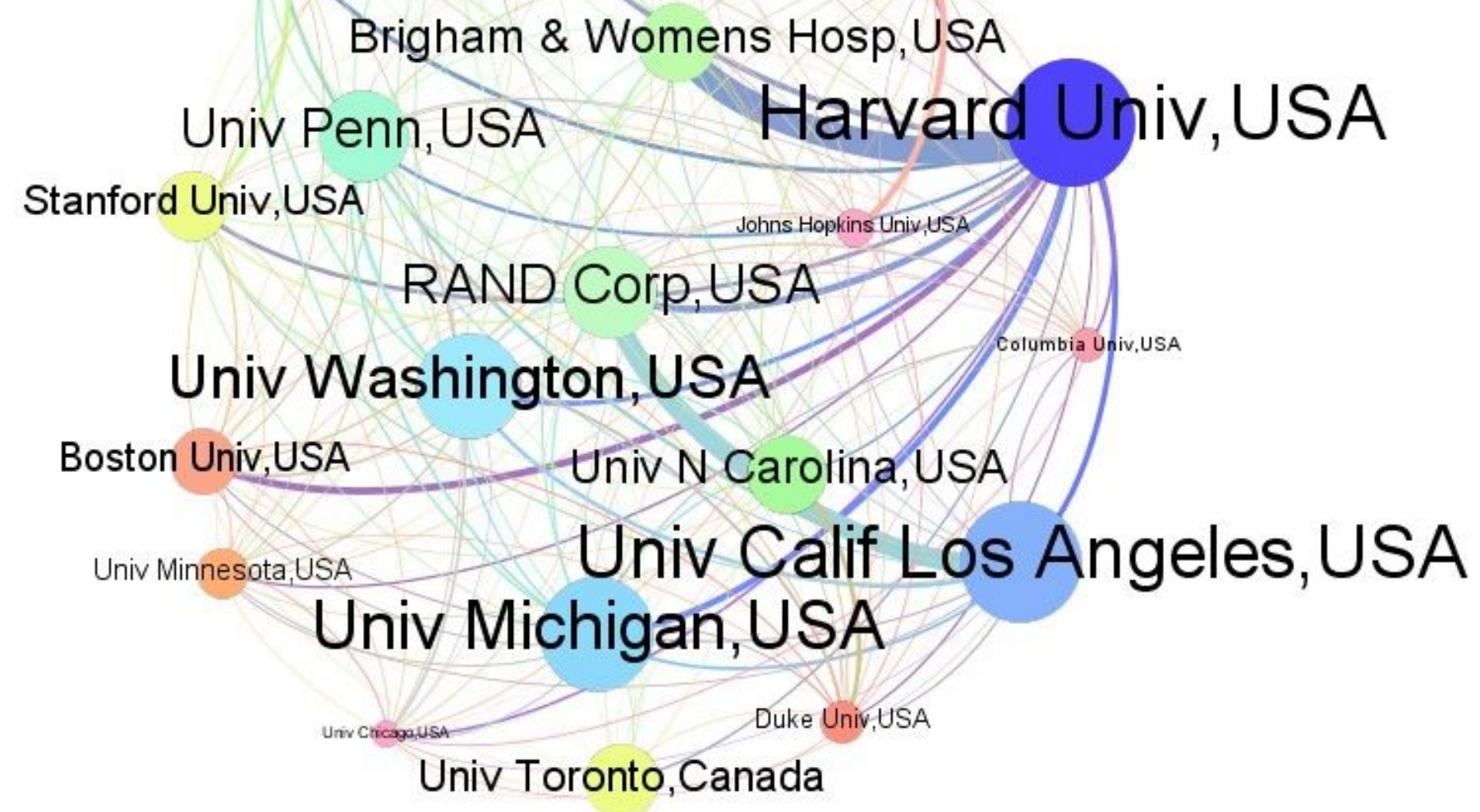

Figure 3

Collaboration network of the top 20 most productive institutions 